ORIGINAL ARTICLE

\title{
Reliability, factor structure, and construct validity of the Polish version of the sport imagery ability measure
}

\author{
Dagmara Budnik-Przybylska ${ }^{1 \cdot A, B, C, D, E, F, G}$, Karol Karasiewicz ${ }^{2 \cdot C, D, E}$, Tony Morris ${ }^{3 \cdot A, D, E, F}$, \\ Anthony Watt ${ }^{4 \cdot A, C, D, E, F}$ \\ 1: Department of Sport Psychology, University of Gdansk, Gdansk, Poland \\ 2: Department of Psychometrics and Statistics, University of Gdansk, Gdansk, Poland \\ 3: College of Sport and Exercise Science and Institute of Sport, Exercise, and Active Living (ISEAL), Victoria University, \\ Melbourne, Australia \\ 4: College of Education and Institute of Sport, Exercise and Active Living (ISEAL), Victoria University, Melbourne, \\ Australia
}

\section{BACKGROUND}

An important component of mental training in sport is the utilization of positive imagery. The "human brain cannot distinguish between an imagined experience and a real experience. The same areas of the brain light up in an imagined experience or imagined performance as in a real experience or performance. For that reason, positive performance imagery has enormous potential" (Orlick, 2008, p. 101). Imagery "has been described as a centre pillar of applied sport psychology" research (Morris, Spittle, \& Perry, 2004, p. 344). The aim of the present study was to examine reliability and validity characteristics of the Polish language version of the Sport Imagery Ability Measure (SIAM).

PARTICIPANTS AND PROCEDURE

Polish athletes $(N=316)$ from a range of sports and competitive levels completed the 48 item SIAM. The participants (163 male, 153 female) were aged between 12 and 57 years $(M=22.15, S D=8.25)$.
RESULTS

Results indicated that the SIAM had sound internal consistency and maintained good stability over a 3-week period. Confirmatory factor analysis demonstrated that the a priori 3 -factor structure of the SIAM resulted in a set of acceptable and poor fit indices $(\mathrm{CFI}=.91, \mathrm{NFI}=.90, \mathrm{RMSEA}=.12)$. Finally, differences in athletes' imagery abilities were examined in relation to competitive level, gender, and age.

\section{CONCLUSIONS}

Overall, results generally supported the reliability and construct validity of the Polish version of the SIAM.

\section{KEY WORDS}

imagery; psychometrics; athletes; sport

Corresponding Author - Dagmara Budnik-Przybylska, Ph.D., Department of Sport Psychology, University of Gdansk,

4 Bażyńskiego Str., 80-952 Gdańsk, Poland, e-mail: psydbu@univ.gda.pl

AUthors' Contribution - A: Study design · B: Data collection · C: Statistical analysis · D: Data interpretation ·

E: Manuscript preparation · F: Literature search · G: Funds collection

to Cite this ARTICle - Budnik-Przybylska, D., Karasiewicz, K., Morris, T., \& Watt, A. (2014). Reliability, factor structure,

and construct validity of the Polish version of the sport imagery ability measure. Current Issues in Personality

Psychology, 2(4), 196-207.

RECEIVED 13.10.2014 · REVIEWED 07.11.2014 · ACCEPTED 12.11.2014 · PUBLISHED 08.12.2014 


\section{BACKGROUND}

An important component of mental preparation in sport is the utilization of imagery skills. It is also considered as a critical domain of applied sport psychology research (Morris, Spittle, \& Perry, 2004) and has substantial potential for performance enhancement. Research and applied work has also shown that imagery processing in relation to sport can be improved through training (Morris, Spittle, \& Watt, 2005), and integrated within many aspects of the psychological preparation of athletes, such as mental warm-up, pre-competition routine, problem solving, strategy development, and coping with pain and injury. As with all applied work in psychology accurate assessment of the characteristics of interest, such as imagery, is important.

The capacity for self-management of imagery processing, therefore, is important if athletes are to maximize the efficacy of an imagery-training program. An important early phase in this process is determining athletes' imagery ability. Morris et al. (2004, p. 21) further delineated imagery ability as "the capacity of the individual to create images, and is typically evaluated in terms of generational, sensorial and emotional qualities". Athletes are only in a position to apply imagery for performance enhancement when they have at least moderate capacity to create clear images, sustain them, and control them in a range of sensory modalities. Thus, measuring imagery ability is critical in research and practice in sport.

Imagery ability is normally assessed from scores on a specific set of mental-ability tasks or from answers to questionnaires that require behavioral or emotive imagery responses (Sheehan, Ashton, $\&$ White, 1983). An overview of the sport psychology literature confirms that subjective approaches utilizing self-report questionnaires represent the most regularly adopted method to discern the key aspects of imagery ability. This format has been consistently integrated into a range of measures developed within the sport and motor performance domains. Questionnaires constructed for use in the motor skills domain include the Movement Imagery Questionnaire (MIQ; Hall, Pongrac, \& Buckolz, 1985), Movement Imagery Questionnaire-Revised (MIQ-R; Hall \& Martin, 1997), the Movement Imagery Questionnaire-3 (MIQ-3, Williams et al., 2012), Vividness of Movement Imagery Questionnaire (VMIQ; Isaac, Marks, \& Russell, 1986) and revised Vividness of Movement Imagery Questionnaire-2 (VMIQ-2; Roberts, Callow, Hardy, Markland, \& Bringer, 2008). All these questionnaires, however, only assess imagery ability associated with general motor movements and were not constructed to examine images related to sport. This raises concerns about ecological validity for the assessment of imagery ability in skilled sports performers (Bhasa- vanija, Vongjaturapat, Morris, \& Muangnapo, 2011). Furthermore, the imagery characteristics focused upon within these measures are limited to a single dimension (vividness), imagery perspective, and two sense modalities (visual and kinaesthetic).

The psychometric properties of these measures have typically been demonstrated using internal consistency and test-retest reliabilities, and to a lesser extent via exploratory factor analysis (EFA) for the MIQ and confirmatory factor analysis (CFA) for the VMIQ-R. Internal consistency, for the VMIQ ranged from $r=.96$ (external perspective subscale) to $r=.97$ (total scale) (Eton, Gilner, \& Munz, 1998) and $r=.95$ for the visual subscale and $r=.97$ for the kinesthetic subscale (Lequerica, Rapport, Axelrod, Telmet, \& Whitman, 2002). For the MIQ, the internal consistency coefficient ranged from $r=.87$ to $r=.89$ (visual) and $r=.86$ to $r=.91$ (kinesthetic) (Atienza, Balaguer, \& Garcia-Merita, 1994; Hall et al., 1985). For the MIQ-R, internal consistency was reported as very good $r=.87$ for the visual and $r=.88$ for the kinaesthetic subscale. A test-retest coefficient of $r=.76$ has been reported over a 3-week period (Isaac et al., 1986) and of $r=.62$ over a 2-week period for VMIQ (Eton et al., 1998). Hall et al. (1985) reported a test-retest reliability of $r=.83$ for the MIQ over a 1-week interval. Exploratory factor analysis revealed a bifactiorial (visual, kinesthetic) structure for the MIQ (Atienza et al., 1994). Roberts et al. (2008) used CFA and confirmed the factorial validity of the 12-item version of the VMIQ-R. Overall, these measures have demonstrated adequate reliability and validity for use in relation to movement imagery abilities.

Measures developed specifically for use within the sport domain include the Sport Imagery Questionnaire (SIQ; Martens, 1982), modified versions of the SIQ (Vealey, 1986; Vealey \& Walter, 1993; Vealey \& Greenleaf, 1998), the Motivational Imagery Ability Measure for Sport (MIAMS; Gregg \& Hall, 2006), the Sport Imagery Ability Questionnaire (SIAQ; Williams \& Cumming, 2011), The Imagination in Sport Questionnaire (KWS; Budnik-Przybylska, 2014) and the Sport Imagery Ability Measure (SIAM; Watt, Morris, \& Andersen, 2004). The SIQ (Martens, 1982) is a multimodal and multidimensional test rating visual, kinesthetic, and auditory imagery, and mood associated with imagery. Although widely used in practice, Martens' SIQ was never validated (Morris et al., 2005). The MIAMS (Gregg \& Hall, 2006) was developed to measure participants' imaging abilities associated with ease and level of emotion experienced following the generation of eight motivational general images [i.e., four MG-A (motivational general arousal) and four MG-M (motivational general mastery) images]. Satisfactory fit indices supported a 2-factor measure, consisting of MG-M and MG-A imagery, with each factor assessed on two rating scales, emotion and ease, each with internal consistencies above $r=.70$ 
(Gregg \& Hall, 2006). However, MIAMS is limited to the assessment of motivational general imagery ability only, to the exclusion of abilities associated with motivational specific imagery. It also does not include any measurement of cognitive imagery, imagery associated with the performance of skills (cognitive specific) and the use of strategies (cognitive general), which are key factors in sport performance. The SIAQ is a questionnaire developed for assessing sport-specific images and simultaneously measuring cognitive and motivational imagery ability associated with the five functions of athlete imagery use: skill, strategy, goal, affect, and mastery sport imagery ability. The SIAQ demonstrates good factorial validity for the five subscale model. Internal reliability was demonstrated with composite reliability ranging from .76 to .86 , and average variance extracted values ranging from .51 to .68. Temporal reliability assessed over a 3-month period resulted in the following coefficients for skill (.83), strategy (.86), goal (.86), affect (.75), and mastery (.85). However, the SIAQ does not consider a broad range of generational and sensorial imagery characteristics and the developers have reported the questionnaire will benefit from further validation (Williams \& Cumming, 2011).

The KWS is a valid and reliable sport imagery ability measure which combines both features of imagery ability and aspects of imagery use. It consists of 7 subscales including physiological feelings, sensory modalities, ease/control, perspective, affirmations, visual, and general. Results indicated the KWS maintained good stability and internal consistency over a 3-week period. Results of CFA suggested that the 7-factor structure of the Imagination in sport questionnaire resulted in acceptable model fit indices (Budnik-Przybylska, 2014).

Watt, Morris, and Andersen (2004) developed a questionnaire to measure imagery ability in sport that expanded on Martens' (1982) SIQ by revising the scenes to make them more generic and applicable to a larger variety of sports, and including items related to all sense modalities and a wider range of dimensions. This approach was considered by Watt et al. to be an important strategy in addressing the limitations of previous measures that considered only one or two senses and a small set of dimensions. As an outcome of this approach, the SIAM consists of four generic sport-related scenes, each of which is imagined by participants for 60 seconds. After imagining each scene, participants are instructed to respond to 12 items that assess five imagery dimensions, namely vividness, control, ease of generation, speed of generation, and duration, six senses, namely visual, auditory, kinesthetic, olfactory, gustatory, and tactile sense, and the experience of emotions. Ratings are made on analogue $100 \mathrm{~mm}$ scales on which athletes place a cross between two extremes, such as "no image" at the left end to "perfectly clear image" at the right end for vividness. Summing the four scores on each dimension produces a subscale score for that dimension of imagery ability.

The SIAM was originally validated in studies with Australian athletes incorporating an EFA study, a CFA study, a convergent and discriminant validity study, and a construct validity study (Watt \& Morris, 2001). Studies of the reliability and validity of the SIAM have produced robust results across translations from the original English version into other languages, including Finnish (Elfving, Riches, Lintunen, Watt, \& Morris, 2001), Thai (Vongjaturapat et al., 2010), Swedish (Weibull, Johnson, \& Watt, 2009), and Hebrew (Goldzweig, Gamliel, \& Peer, 2009). Psychometric studies of the SIAM in those languages revealed strong internal consistency for the 12 subscales, with alphas rarely below .70 for specific subscales. Adequate test-retest reliability was also reported in several studies (Bhasavanija et al., 2011).

Previously, researchers have considered findings associated with the examination of differences in imagery ability between a variety of categorizations of athlete samples (e.g., sport type, competition level, gender). Results highlighting significant differences between athletes performing at various levels of elite and non-elite sport competition have been reported regularly. Typically, researchers have indicated that athletes participating at higher levels of competition scored higher on imagery ability than athletes participating at the recreational level (e.g., Bhasavanija et al., 2011; Gregg \& Hall, 2006; Elfving et al., 2001; Oishi \& Maeshima, 2004; Roberts et al., 2008; Watt \& Morris, 2001; Williams \& Cumming, 2011). High-level athletes reported greater vividness (Eton et al., 1998; Isaac \& Marks, 1994; Oishi \& Maeshima, 2004) and kinesthetic imagery ability. Hardy and Callow (1999) found that high-level performers also reported a higher level of kinesthetic imagery and suggested that this may be due to the assistance kinesthetic imagery provides them in acquiring a detailed feel for movements. Furthermore, imagery is a skill that improves with practice (Rodgers, Hall, \& Buckolz, 1991), and athletes of a higher competitive level use it and practice it more frequently and deliberately (Cumming \& Hall, 2002). Williams and Cumming (2011) also confirmed that the subscale variables of the SIAQ of skill strategy, goal, and mastery images were significant predictors of competitive level.

Researchers have identified that males and females vary only minimally in their imaging abilities (e.g., Bhasavanija et al., 2011; Campos, Pérez-Fabello, \& Gómez-Juncal, 2004; Gregg \& Hall, 2006; Hall, 2001; Richardson, 1994, 1999). Williams and Cumming (2011) found a significant difference in SIAQ mastery imagery between male $(M=5.10$, $S D=1.06)$ and female $(M=4.73, S D=1.01)$ scores for this characteristic. The researchers further reported 
that, "closer analysis of the structural matrix confirmed only mastery images (.74) predicted gender, with skill, strategy, goal, and affect imagery acting as poor predictors" (p. 431). There is also little evidence of significant differences in imagery ability comparing sport type (individual or team sport), possibly because some disciplines incorporate both individual and team aspects (Gregg \& Hall, 2006). Furthermore, researchers have not frequently reported differences in imagery abilities between athletes of different ages (Bhasavanija et al., 2011).

The main purpose of the current study was to examine the psychometric properties of a Polish language version of the SIAM, to further substantiate its veracity as a multi-modal, multidimensional measure of imagery specifically operationalised within the sport context. The first aim of the study addressed translating the SIAM and confirming the accuracy and consistency of meaning of the Polish version with the original English version. The second aim of the study was to examine the internal consistency, test-retest reliability, and factor structure of the translated measure with a sample of Polish athletes. In addition, differences in athletes' imagery ability were examined across competitive level, and in relation to both gender and age, as an indication of the construct validity of the measure.

\section{PARTICIPANTS AND PROCEDURE}

\section{PARTICIPANTS}

Participants involved in the validity and internal consistency analyses were recruited from primary and secondary schools offering specialist sport programs, Gdansk University of Physical Education and Sport, University of Gdansk, and elite sporting groups. The cohort represented a convenience sample of 326 athletes, however following the deletion of participants' incomplete responses, the final SIAM items data set comprised the responses of 316 participants (163 male, 153 female), aged between 12 and 57 years $(M=22.15$, $S D=8.25)$. This sample was also categorized into three age groups of under $15(n=64), 16-20(n=85)$ and above $20(n=167)$. These age groups were determined on the basis of developmental psychology classifications of early adolescence, late adolescence, and adulthood, and established age outlined in relation to Polish populations by Brzezińska, Appelt, and Ziółkowska (2008). From a sport perspective, this type of grouping could also be considered to be matched with patterns of physical development. Athletes were also classified at a range of competition levels, including local/district $(n=88)$, state $(n=81)$, and national $(n=102)$, representing a variety of sports disciplines, including football, sailing, basketball, track and field, volleyball, and swimming. A group of 32 athletes from the origi- nal sample were recruited to complete the SIAM again after a 3-week interval to test the stability of the SIAM over time.

\section{MEASURES}

Demographic Form. Demographic information was collected using six items to source data associated with gender, age, the sport/s in which each athlete was primarily involved, and competition level of their participation.

Sport Imagery Ability Measure (SIAM) (Watt, 2003; Watt et al., 2004). As described in the introduction, the SIAM is a measure that examines 12 items, reflecting five dimensions, six sense modalities, and emotion, related to imagery ability. Respondents provide self-report ratings of 12 imagery ability items, one reflecting each dimension, sense modality, and emotion, following 60 seconds imagining each of four generic sports scenes.

The first stage of the study involved translating the SIAM into Polish based on all the following guidelines: (a) Direct translation by a professional translator who was not familiar with the instrument; (b) examination of that version by a panel of academics familiar with the original measure, and competent Polish-English language speakers; (c) implementation of corrections suggested by the panel; (d) return of the modified version to the translator who translated this version back into English; (e) consideration of the back-translated version by the researchers, and (f) resolution of any minor concerns about translation. This translated version was used in a pilot administration during academic mental training classes with a sample of 30 students. They reported no problems with comprehension and quality of the translated version, so it was used in the main study.

\section{PROCEDURE}

The University of Gdansk Human Research Ethics Committee approved the study. The authors received permission for the Polish adaptation of the SIAM from the author of the test. Following the provision of information regarding the study by the lead investigator to the school, university, and sporting club groups, volunteer participants completed standard consent documents. Written consent was obtained from athletes over 18 years, and a parent or person with care responsibilities in the case of minors. The treatment of athletes was in accordance with APA ethical guidelines. Participants completed the SIAM and provided their demographic information in a quiet environment, usually at their education or training facilities. Participants completed the materials individually or in small groups and then returned 
them to the investigators. Data collection took approximately 20 minutes. Athletes recruited for the test-retest reliability procedure completed the SIAM under the same conditions on two occasions separated by a 3-week interval.

\section{DATA ANALYSIS}

Descriptive, reliability, correlational, and inferential analyses were conducted using SPSS version 21 . Relationships between subscales, and the time stability of the SIAM were calculated using Pearson's correlation coefficient. A value of $r>.70$ is considered to be indicative of adequate test-retest reliability (Kline, 2000). Internal consistency of each of the 12 SIAM subscales was examined using Cronbach's $\alpha$ coefficient. Independent samples $t$-tests were used to examine gender differences in imagery ability for each of the SIAM subscales, Univariate Analyes of Variance (ANOVA) and Bonferroni post-hoc tests were performed to examine differences in athletes' imagery ability among competitive levels and age groups. ANOVA was used in preference to Multivariate Analyses of Variance (MANOVA) for the inferential analyses due to large variation in the pattern of the correlations observed between the subscale scores (i.e., dependent variables), thus, violating assumptions associated with linearity and multicollinearity (Hair, Black, Babin, \& Andersen, 2010).
Confirmatory factor analysis was conducted using AMOS 21 for Windows and the maximum likelihood estimation. To determine the fit of the model, we considered different indices of fit that included normed $\chi^{2}(\mathrm{NC})$, the adjusted goodness of fit index (AGFI), the normed fit index (NFI), the comparative fit index (CFI), the Tucker-Lewis Index (TLI), the standardized root mean square residual (SRMR) and the root mean square error of approximation (RMSEA). An acceptable model fit is inferred when NC is less than 5; AGFI is higher than .80; NFI, TLI, and CFI are higher than .90; and the RMSEA is close to .08 (Hooper, Coughlan, \& Mullen, 2008; Hu \& Bentler, 1999). These indices were selected on the basis of the examination of the structural equation modelling literature associated with the best practice determination of model fit, whereby, the indices are representative of the absolute fit, incremental fit, and model parsimony categories (e.g., Hair et al., 2010; Hooper et al., 2008).

\section{RESULTS}

\section{DESCRIPTIVE STATISTICS}

The means and standard deviations for each of the SIAM subscales for the total sample and for each of the gender, age, and competitive level subgroups are shown in Tables 1 and 2. Subscale scores for each par-

Table 1

Means and standard deviations for the 12 subscales of the total sample, for males and females and for age groups

\begin{tabular}{|c|c|c|c|c|c|c|c|c|c|c|c|c|}
\hline & \multirow{2}{*}{\multicolumn{2}{|c|}{ Total }} & \multicolumn{4}{|c|}{ Gender } & \multicolumn{6}{|c|}{ Age } \\
\hline & & & \multicolumn{2}{|c|}{$\begin{array}{l}\text { female } \\
n=153\end{array}$} & \multicolumn{2}{|c|}{$\begin{array}{c}\text { male } \\
n=163\end{array}$} & \multicolumn{2}{|c|}{$\begin{array}{c}\text { under } 16 \\
n=64\end{array}$} & \multicolumn{2}{|c|}{$\begin{array}{c}16-20 \\
n=85\end{array}$} & \multicolumn{2}{|c|}{$\begin{array}{c}\text { above } 20 \\
n=167\end{array}$} \\
\hline & $M$ & $S D$ & $M$ & $S D$ & $M$ & $S D$ & $M$ & $S D$ & $M$ & $S D$ & $M$ & $S D$ \\
\hline Control & 289.60 & 64.24 & 293.63 & 64.38 & 285.83 & 64.08 & 303.33 & 62.79 & 292.45 & 70.16 & 282.90 & 61.01 \\
\hline Ease & 296.45 & 64.83 & 300.69 & 66.95 & 292.46 & 62.73 & 300.38 & 64.91 & 305.73 & 66.97 & 290.22 & 63.39 \\
\hline Speed & 305.93 & 64.72 & 307.81 & 64.59 & 304.17 & 64.99 & 302.41 & 68.12 & 312.66 & 67.56 & 303.86 & 62.01 \\
\hline Duration & 253.68 & 78.15 & 254.28 & 79.09 & 253.12 & 77.50 & 288.75 & 76.99 & 240.15 & 78.36 & 247.13 & 74.98 \\
\hline Visual & 303.30 & 64.80 & 307.08 & 65.93 & 299.75 & 63.71 & 304.64 & 63.16 & 306.54 & 69.05 & 301.14 & 63.48 \\
\hline Auditory & 222.78 & 92.04 & 233.80 & 90.09 & 212.43 & 92.92 & 244.44 & 93.78 & 225.33 & 102.11 & 213.18 & 84.76 \\
\hline Kinasth & 234.69 & 89.78 & 237.40 & 92.51 & 232.15 & 87.35 & 251.09 & 99.57 & 232.27 & 83.81 & 229.63 & 88.58 \\
\hline Olfactory & 150.26 & 95.48 & 153.98 & 101.69 & 146.76 & 89.42 & 139.11 & 94.74 & 154.06 & 103.42 & 152.59 & 91.75 \\
\hline Gustation & 142.19 & 91.97 & 149.38 & 97.13 & 135.44 & 86.60 & 138.81 & 83.05 & 148.79 & 99.56 & 140.13 & 91.58 \\
\hline Tactile & 251.49 & 84.39 & 253.75 & 89.44 & 249.36 & 79.58 & 275.95 & 77.13 & 252.88 & 86.38 & 241.40 & 84.54 \\
\hline Emotion & 266.48 & 76.24 & 270.53 & 79.23 & 262.68 & 73.37 & 278.17 & 84.26 & 272.49 & 75.30 & 258.94 & 73.06 \\
\hline Vividness & 296.75 & 64.92 & 298.31 & 65.07 & 295.29 & 64.93 & 293.91 & 65.13 & 299.15 & 69.24 & 296.62 & 62.88 \\
\hline
\end{tabular}


Table 2

Means, standard deviations and post-hoc analysis for the 12 subscales among the groups of different sport level

\begin{tabular}{|c|c|c|c|c|c|c|c|c|}
\hline \multirow[t]{2}{*}{ Subscale } & \multicolumn{2}{|c|}{$\begin{array}{l}\text { 1. Local/district } \\
(n=88)\end{array}$} & \multicolumn{2}{|c|}{$\begin{array}{l}\text { 2. State } \\
(n=81)\end{array}$} & \multicolumn{2}{|c|}{$\begin{array}{l}\text { 3. National } \\
(n=102)\end{array}$} & \multirow[t]{2}{*}{$F$} & \multirow[t]{2}{*}{ Post-hoc } \\
\hline & $M$ & $S D$ & $M$ & $S D$ & $M$ & $S D$ & & \\
\hline Vividness & 282.47 & 62.78 & 300.89 & 69.20 & 306.30 & 63.85 & 3.37 & $1 \mathrm{v} 3^{*}$ \\
\hline Control & 276.75 & 66.51 & 294.85 & 67.86 & 300.95 & 61.64 & 3.44 & $1 \mathrm{v} 3^{*}$ \\
\hline Ease & 282.14 & 60.77 & 306.37 & 69.50 & 309.42 & 57.53 & 5.19 & $1 \mathrm{v} 2^{*}, 1 \mathrm{v} 3^{*}$ \\
\hline Speed & 287.75 & 63.23 & 313.93 & 68.96 & 316.68 & 62.05 & 5.51 & $1 \mathrm{v} 2^{*}, 1 \mathrm{v} 3^{*}$ \\
\hline Duration & 243.38 & 79.12 & 269.67 & 79.96 & 258.18 & 74.96 & 2.43 & $1 \mathrm{v} 2^{*}$ \\
\hline Visual & 289.86 & 66.14 & 311.25 & 67.50 & 311.52 & 61.94 & 3.26 & $1 \mathrm{v} 2^{*}, 1 \mathrm{v} 3^{*}$ \\
\hline Auditory & 209.82 & 82.26 & 242.80 & 99.85 & 223.61 & 95.30 & 2.68 & $1 \mathrm{v} 2^{*}$ \\
\hline Kinasthetic & 220.95 & 92.30 & 243.26 & 92.79 & 242.54 & 83.94 & 1.79 & \\
\hline Olfactory & 148.18 & 92.92 & 155.28 & 102.64 & 144.67 & 92.59 & 0.28 & \\
\hline Gustation & 142.60 & 83.49 & 143.91 & 98.86 & 140.85 & 94.22 & 0.03 & \\
\hline Tactile & 249.28 & 75.23 & 271.09 & 81.56 & 253.00 & 87.96 & 1.70 & \\
\hline Emotion & 257.22 & 75.65 & 284.37 & 80.70 & 268.02 & 67.13 & 2.86 & $1 \mathrm{v} 2^{*}$ \\
\hline
\end{tabular}

Note. ${ }^{*} p<.05$

ticipant were derived by totaling the four individual scene items representing that subscale (e.g., the four auditory items or the four duration items), resulting in a possible score range of 0-400.

Generally, the subscale scores followed a similar pattern for each of the groups with respect to means and standard deviations. The pattern of subscale scores was also similar to the pattern found in descriptive statistics of the original measure (Watt et al., 2004). Mean scores for the sensory subscales (except for the visual) were lower than scores on the dimension subscales. Typically, there was less variability in the dimensional subscales than in the sensory subscales (excluding visual). Within each subgroup, the scores of the gustatory and olfactory subscales were substantially lower and showed greater variability than other subscales. The speed subscale scores were the highest for the total sample and subgroups except for the local/district level and youngest subgroups. In general, only small differences in mean score maximums existed between the speed and the visual subscale for all groups. Overall, the lowest scores for the total sample and all subgroups were found for the gustatory subscale.

\section{FACTORIAL VALIDITY}

Confirmatory factor analysis was conducted to examine an a priori 3-factor structure of the SIAM constructed for the data set predicted on the basis of CFA

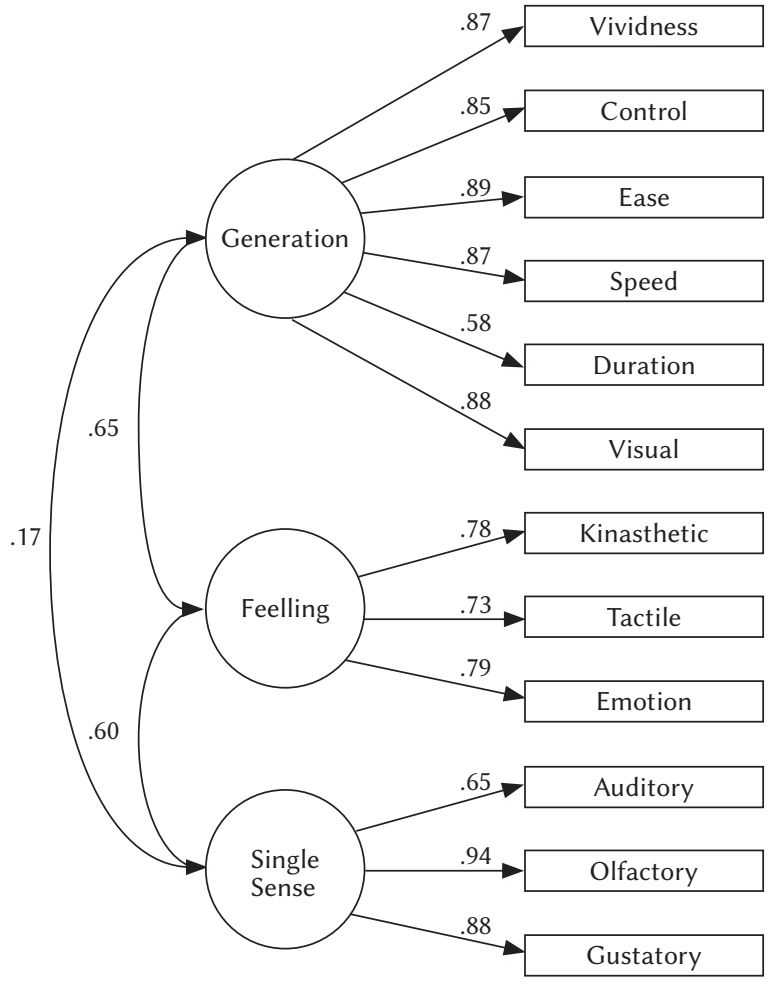

Figure 1. The standardized - solution values of 12-subscale model of the SIAM.

results from the Australian, Finnish, Thai, Swedish, and Israeli validation studies. In the a priori model, presented as Figure 1, we assumed that the 12 dimensions would load on three latent factors. Factor 1, la- 
Table 3

Subscale Inter-Correlation

\begin{tabular}{|c|c|c|c|c|c|c|c|c|c|c|c|}
\hline Subscale & 1 & 2 & 3 & 4 & 5 & 6 & 7 & 8 & 9 & 10 & 11 \\
\hline \multicolumn{12}{|l|}{ Vividness (1) } \\
\hline Control (2) & $.68^{* *}$ & & & & & & & & & & \\
\hline Ease (3) & $.74^{* *}$ & $.80^{* *}$ & & & & & & & & & \\
\hline Speed (4) & $.72 * *$ & $.75^{* *}$ & $.82^{* *}$ & & & & & & & & \\
\hline Duration (5) & $.47^{* *}$ & $.49^{* *}$ & $.52^{* *}$ & $.44^{* *}$ & & & & & & & \\
\hline Visual (6) & $.86^{* *}$ & $.70^{* *}$ & $.73^{* *}$ & $.75^{* *}$ & $.48^{* *}$ & & & & & & \\
\hline Auditory (7) & $.34^{* *}$ & $.38^{* *}$ & $.33^{* *}$ & $.27^{* *}$ & $.32^{* *}$ & $.32^{* *}$ & & & & & \\
\hline Kinasthetic (8) & $.38^{* *}$ & $.39 * *$ & $.33^{* *}$ & $.26^{* *}$ & $.32^{* *}$ & $.36^{* *}$ & $.58^{* *}$ & & & & \\
\hline Olfactory (9) & $.14^{*}$ & $.15^{* *}$ & .11 & .05 & $.19^{* *}$ & .09 & $.58^{* *}$ & $.50 * *$ & & & \\
\hline Gustatory (10) & $.15^{* *}$ & $.16^{* *}$ & $.14^{*}$ & .07 & $.17^{* *}$ & $.12^{*}$ & $.57^{* *}$ & $.44^{* *}$ & $.82^{* *}$ & & \\
\hline Tactile (11) & $.52^{* *}$ & $.52^{* *}$ & $.47^{* *}$ & $.41^{* *}$ & $.42^{* *}$ & $.49^{* *}$ & $.48^{* *}$ & $.54^{* *}$ & $.36^{* *}$ & $.35^{* *}$ & \\
\hline Emotion (12) & $.49^{* *}$ & $.44^{* *}$ & $.46^{* *}$ & $.37^{* *}$ & $.36^{* *}$ & $.51^{* *}$ & $.53^{* *}$ & $.65^{* *}$ & $.38^{* *}$ & $.29^{* *}$ & $.57^{* *}$ \\
\hline
\end{tabular}

Note. ${ }^{*}$ Correlation is significant at the .01 level (2-tailed). ${ }^{*}$ Correlation is significant at the .05 level (2-tailed).

Table 4

Alpha and time stability correlation values for SIAM subscales

\begin{tabular}{ccc}
\hline Subscale & $\alpha$ & Time-stability \\
\hline Vividness & .87 & .75 \\
Control & .78 & .71 \\
Ease & .73 & .70 \\
Speed & .78 & .70 \\
Duration & .80 & .64 \\
Visual & .90 & .76 \\
Auditory & .76 & .72 \\
Kinasthetic & .81 & .63 \\
Olfactory & .88 & .63 \\
Gustatory & .81 & .71 \\
Tactile & .86 & .65 \\
Emotion & .76 & .59 \\
\hline
\end{tabular}

beled dimensions and visual sense, consisted of the visual sense subscale, and the vividness, control, ease, speed, and duration dimension subscale scores. Factor 2 was labeled single organ senses and represented the specific senses of audition, olfaction, and gestation. Factor 3 was labeled feeling senses, and represented senses associated with feeling, specifically derived from the kinesthetic, tactile, and emotion subscale scores. Results indicated that the a priori stated structure of SIAM demonstrated tenable fit to the Polish data. Confirmatory factor analysis of the three factor structure resulted in fit indices of $\mathrm{NC}=5.74$, AGFI $=.80$, RMSEA $=.12, \mathrm{NFI}=.90, \mathrm{TLI}=.89$, and $\mathrm{CFI}=.91$.

Table 3 presents the correlation matrix among the 12 subscales of SIAM. Results show that there is a high degree of variability in the pattern of association between subscales. The highest correlation is between the visual and vividness subscales and the lowest correlation, which is not significant, is between the olfactory and speed subscales.

\section{RELIABILITY}

Reliability characteristics of the measure were evaluated on the basis of the internal consistency and temporal stability for both subscales. Results of internal consistency (Cronbach's $\alpha$ ) and temporal stability (Pearson $r$ ) analyses are presented in Table 4.

The internal consistency estimates (Cronbach's $\alpha$ ) for the 12 SIAM subscales indicated adequate reliability with values all greater than $\alpha=.70$. Test-retest reliability results revealed that all 12 SIAM dimensions, overall SIAM score, and latent factors demonstrated adequate stability over time. Temporal stability subscale correlations ranged from .59 for Emotion to .76 for Visual Modality. The total SIAM test-retest correlation was also very stable $(r=.81)$.

\section{GROUP DIFFERENCES}

Evidence to support the construct validity of the SIAM was generated using independent samples $t$-tests to examine gender differences in subscale scores. 
ANOVA was used to examine differences in imagery ability according to competitive level (local/district, national, state) and age (under 16 years old, 16-20, over 20 years old). For the analyses, the 12 subscales of SIAM served as dependent variables and gender, age categories, and competition level were independent variables.

Results of the independent samples $t$-tests to examine gender differences in the SIAM subscale scores revealed only one significant difference. Males' scores for the auditory subscale were significantly higher than those of females, $t(314)=-2.07$, $p=.039$. The ANOVA examining imagery ability subscale contrasts among participants of the three age cohorts of 15 years old and under, 16-20 years old, and over 20 years old resulted in limited differences. Participants' scores in the groups differed significantly on two dimensions, tactile $(F=3.97, p=.020)$ and duration $(F=8.71, p<.001)$. In both cases post-hoc results revealed that the youngest athletes group reported significantly higher imagery ability scores than the $16-20$ and above 20 groups. There were no significant post-hoc differences for the latter two groups.

Significant differences in imagery ability were found for ANOVA comparisons for competition level for the subscales of vividness, control, ease, speed, duration, visual, auditory, and emotion. Further posthoc analysis for competition level, indicating the pattern of significant contrasts are detailed in Table 4 . In all significant post-hoc differences professional level athletes reported higher imagery ability scores than novice athletes.

\section{DISCUSSION}

The purpose of the present study was to examine the reliability, factor structure, and construct validity of a Polish language version of the SIAM. The first aim was translation of the SIAM and confirmation of the correspondence of the Polish version to the original English version. Athletes' scores on the SIAM were analysed to evaluate the confirmatory factor structure, test-retest reliability, and internal consistency of the measure. Indicators of construct validity were generated by examining group contrasts in relation to gender, age, and skill level within the Polish athlete sample. The results provided tentative support for the psychometric properties of the Polish version of the SIAM and extended the available information regarding athletes' imagery ability within a broader international context.

Following the translation of the SIAM into Polish using a recommended protocol, this version was used in a pilot study. Respondents reported no concerns with comprehension and quality of the Polish SIAM. This process of translation has been consistently adopted in adaptations of both the SIAM and the SIQ (e.g., Ruiz \& Watt, 2014; Vongjaturapat et al., 2010; Watt, Jaakkola, \& Morris, 2006; Weibull et al., 2009) and has demonstrated that consistency between the intent of the original items and meaning be prioritized over an exact literal translation. This is seen to be the advantage of allowing the translation process to be managed by a translator in association with experts in the domain who are first language speakers of the adapted version and who are in consultation with first language English experts who are familiar with the measures. It is recommended that the continued adoption of this protocol occurs both in relation to the SIAM and with reference to other translations of sport imagery measures. Now the Polish version of the SIAM questionnaire is being prepared in a downloadable form.

The general pattern of the imagery ability subscale scores for the Polish sample is similar to that observed in other athletes who completed the original version (Revised SIAM) (Watt, 2003; Watt \& Morris, 1999). In the original version (Watt, 2003), higher scores were observed for the visual, ease, speed, and vividness subscales, and the lowest score was for the gustatory subscale. In the Polish version, higher scores were in the speed, visual, vividness, and ease subscales, with the gustatory subscale again demonstrating the lowest values. Comparable patterns have been found in other non-English adaptations of the SIAM. For example, in the Thai version results indicated that higher scores were for the visual, vividness, ease and speed, and the lowest scores were found for the olfactory and gustatory subscales. Mean subscale values reported for the Swedish version showed higher scores for speed, visual, ease, vividness, and the lowest score for the gustatory subscale. A similar pattern was reported for a Finnish athlete sample with the exception of duration, rather than vividness being reported in the highest four scores. In general, the current Polish subscale patterns reinforce the SIAM as a measure that is capable of representing sport imagery ability characteristics in a manner that typifies the sensorial and dimensional relationships (e.g., visual linked with major modalities; olfactory and gustatory senses' lower involvement in sport imagery) purported in previous overviews of sport imagery ability (e.g., Morris et al., 2005; Watt et al., 2004).

A central element of the present study was the CFA examination using a Polish athlete sample, of the 3-factor model of the SIAM proposed by Watt et al. (2004). Results of CFA indicated that SIAM demonstrates an adequate level of fit to the Polish data for a measure in the initial phase of translation validation. Furthermore, the results are comparable to the Swedish (Weibull et al., 2009), Finnish (Elfving et al., 2001), Thai (Vongjaturapat et al., 2010), and English versions (Watt, 2003). Findings reported for an adult sample of Thai golfers (Bhasavanija et al., 2011) re- 
vealed stronger CFA indices than those found for the Polish sample. Root mean square error of approximation in the Polish version was lower than in English, but similar to Australian and higher than results from Swedish, Finnish, and Thai data. Comparative fit index in the Polish version was equivalent to the English version, but lower than Finish, Thai, Australian, and Swedish. The present CFA results further verify that the 3-factor structure is consistently achievable, and resultant fit indices are comparable to existing international studies. Furthermore, in all adaptations it was possible to demonstrate the coherence of the 12 subscales as observed factors to represent latent factors associated with the three single organ senses, feelings, and imagery generation factors. This model continues to provide a foundation from which the SIAM as an assessment instrument is able to substantiate the multisensory and multidimensional nature of imagery ability in a sport context.

Examining the subscale intercorrelation pattern of the original version of the SIAM showed the highest correlation was between visual and vividness and the lowest was between gustatory and duration (Watt, 2003). For the Polish version the correlation was again highest between visual and vividness subscales, but the lowest correlation was between the olfactory and speed subscales. Similar to the type of associations observed in the CFA, the strongest correlations were between the visual sense and the dimensions. Correlations between the singles senses and the other imagery ability characteristics were typically low. Interestingly, the pattern of correlations for the emotion subscale reported for the Polish data and in the original data highlights a very consistent trend of moderate associations with the generational elements of imagery ability.

A review of the internal consistency values of the original version of the SIAM revealed alpha values that varied from .66 (speed) to .87 (gustatory). Results for the Polish version highlighted acceptable subscale alpha coefficients across a similar range, varying from .73 (ease) to .90 (visual). The internal consistency values of the Polish version are also slightly stronger than values reported for other non-English language versions of the measures. For example, for the Thai version (Bhasavanija et al., 2011) $\alpha$ varied from .54 (gustatory) to .74 (control) and for the Swedish version (Weibull et al., 2009) $\alpha$ values ranged from .62 (ease) to .79 (olfactory). Additionally, temporal consistency of the Polish version of the SIAM was examined across a 3-week interval. Test-retest reliability analyses indicated that the subscale scores maintained an acceptable level of stability. A comparison of the correlation values for the original SIAM (4-week interval) and the Polish version highlighted variations from .41 (auditory) to .76 for gustatory in the original version (Watt, 2003) and from .59 emotion to .76 for visual in the Polish version. Test-re- test reliability of the Thai version (Bhasavanija et al., 2011) was slightly stronger with values varying from .61 (tactile) to .98 (duration) across a 3-week interval. Overall, the resultant data for the Polish SIAM indicate that it is similar in terms of acceptable reliability characteristics to both alternate versions of the SIAM and other movement and sport imagery ability instruments that have been used with athlete groups.

Relevant demographic characteristics, including gender, age, and competition level were examined for differences as an indication of the construct validity of the SIAM. The current results were generally in line with previous imagery studies involving gender comparisons, whereby only limited difference in imagery processing was reported between males and females (Bhasavanija et al., 2011; Campos et al., 2004; Gregg \& Hall, 2006; Hall, 2001; Williams \& Cumming, 2011). Inferential analysis of the imagery ability scores for the three age groups, however, did highlight significant age group differences for the tactile and duration subscales, with younger athletes reporting higher imagery ability. Possible reasons for this limited gender variance within participants who were less than 16 years of age may be as straight-forward as these athletes having experienced issues with comprehension of the meaning of items associated with these characteristics or the more complex perspective that the differences may have been connected with developmental changes. Children have been identified as having a higher capacity for imaginative play, which could possibly lead to higher levels of imagery ability (Orlick, 2004; Vasta, Haith, \& Miller, 1995). Similarly, in previous research (Bhasavanija et al., 2011) with Thai golfers as participants, there were significant differences between young adults (18-24 years) and mature players (45 years on over) on only two of the 12 SIAM dimensions (i.e., duration and control) with the mature golfers reporting higher imagery ability. The most plausible conclusion to draw for the current small number of significant differences identified is in line with the suggestion proposed by Bhasavanija et al. in which age differences for the SIAM subscales could be due to chance as there is no clear basis, conceptually or as an outcome of previous investigations, for these specific age-related variations.

Contrasts for the demographic categorizations associated the competitive level clearly showed that Polish athletes at the national and state levels reported higher imagery ability scores than their local level counterparts. Results indicated that athletes competing at the two higher levels of competition obtained significantly higher scores across all the imagery dimension subscales, and in relation to the visual, auditory and emotion subscales. The post-hoc pattern varied in relation to the competition levels with three subscales (i.e., emotion, duration, auditory) revealing higher scores for state level athletes than the local 
level competitors, and all other significantly different subscales scores revealing a higher value for the national level cohort than the local level players. Previous results associated with international research using the SIAM indicated variability regarding competition level differences. Bhasavanija et al. (2011) reported that for all Thai version SIAM subscales professional golfers scored significantly higher than those golfers who categorized themselves as novices. In contrast, Elfving et al. (2001) found no significant differences between elite and non-elite groups of Finnish athletes on any subscale. Elfving et al. suggested this result may have been due to a substantial difference in group size (i.e., 71 and 212), and the self-reported classifications of skill level participation may not have been directly applicable in the Finnish context. Furthermore, the pattern of results in the present study is also consistent with previous sport imagery research (Arvinen-Barrow, Weigand, Thomas, Hemmings, \& Walley, 2007; Cumming \& Hall, 2002; Gregg \& Hall, 2006; Hall, Mack, Paivio, \& Hausenblas, 1998; Roberts et al., 2008). Those researchers indicated that athletes competing at a higher level use imagery more frequently, and athletes who use imagery more frequently, characterize higher levels of imagery ability.

Results of the present study provide positive support for the psychometric properties of the SIAM for administration with Polish athletes. This is the first Polish adaptation of an imagery ability questionnaire and it should serve as a useful resource for research and applied work as a screening device, and for pretest and post-test intervention studies designed to enhance imagery ability. In applied work it can be used to improve the efficacy of imagery training programs by providing information to support program design and modification. The SIAM could serve to control for differences in imagery abilities before treatment, to ensure that performance differences as an outcome of training are more likely due to the program and not because of pre-program differences in imagery abilities.

Limitations of the present research are primarily related to the convenience sampling. Firstly, the number of participants in specific age groups could have been balanced more to support a more definitive analysis of the age limits for which the SIAM is applicable. It should be noted that in particular sport disciplines, such as gymnastics, younger athletes participate at the highest competitive level and a measures like the SIAM must be capable of producing reliable and valid data from adolescents, if it is to be used in practice with this age cohort. Secondly, the recruitment of participants according to sport type was not systematic. This meant that certain sports were over or under represented in the sample. Research presented by Ruiz and Watt (2014) proposed that studies in the imagery domain associated with psychometric evaluation should work towards recruitment in which similar numbers of athletes are selected with reference to sport type, competitive level, task type, and function.

Future research should focus on further psychometric validation of the SIAM. Lack of clarity regarding the CFA fit remains, whereby the complete set of indices cannot go beyond tentative support for the 3-factor model. More intensive model respecification based on modification indices and the possible incorporation of shared variance between observed variables may improve the fit of the 3-factor model. Data could be collected using the SIAM with specific ages and groups of athletes, for example, one discipline or team and individual sport and the involvement of age groups representative of the elite levels for that sport. Additionally, research should be directed toward establishing concurrent and convergent validity of the SIAM, comparing the Polish version with other sport imagery ability questionnaires and sport imagery use questionnaires. More extensive construct validity research is probably the most critical area for further psychometric study of the SIAM. In particular, it would be valuable to conduct research using established techniques that have been demonstrated to enhance imagery ability. Measurement of imagery ability using the SIAM before and after the imagery-training program would determine whether the SIAM reflects changes consistent with the imagery training, thus supporting validity of the measure.

\section{CONCLUSIONS}

The current findings have provided valuable support for a Polish language version the SIAM. This will provide the capacity for researchers in this country to pursue more in-depth investigations of the sport imagery construct with athletes for whom the original version of the SIAM may not have been suitable. In addition, sport psychologists in Poland will be able to use the SIAM to help develop imagery-training programs to suit individual athletes.

\section{RefERENCES}

Arvinen-Barrow, M., Weigand, D., Thomas, S., Hemmings, B., \& Walley, M. (2007). Elite and novice athletes' imagery use in open and closed sports. Journal of Applied Sport Psychology, 19, 93-104.

Atienza, F., Balaguer, I., \& Garcia-Merita, M. L. (1994). Factor analysis and reliability of the Movement Imagery Questionnaire. Perceptual and Motor Skills, 78, 1323-1328.

Bhasavanija, T., Vongjaturapat, N., Morris, T., \& Muangnapo, P. (2011). Validation of the Sport Imagery Abil- 
ity Measure in Thai for golf. Thai Journal of Sports Sciences, 8, 1-18.

Brzezińska, A. I., Appelt, K., \& Ziółkowska, B. (2008). Psychologia rozwoju człowieka [Psychology of human development]. In: J. Strelau, \& D. Doliński (ed.), Psychologia. Podręcznik akademicki [Psychology. Academic Handbook] (pp. 96-292). Gdańsk: Gdańskie Wydawnictwo Psychologiczne.

Budnik-Przybylska, D. (2014). The Imagination in Sport Questionnaire - reliability and validity characteristics. Current Issues in Personality Psychology, 2, 68-80.

Campos, A., Pérez-Fabelo, M. J., \& Gómez-Juncal, R. (2004). Gender and age differences in measured and self-perceived imaging capacity. Personality and Individual Differences, 37, 1383-1389.

Cumming, J., \& Hall, C. (2002). Deliberate imagery practice: The development of imagery skills in competitive athletes. Journal of Sports Sciences, 20, 137-145.

Elfving, T., Riches, D., Lintunen, T., Watt, T., \& Morris, T. (2001). Reliability, factor structure and criterion validity of the Sport Imagery Ability Measure (SIAM) in athletes from Finland. In: A. Papaioannou, M. Goudas, \& Y. Theodorakis (eds.), Proceeding of the Xth World Congress of Sport Psychology, 2, 49-51. Athens, Greece: ISSP.

Eton, D. T., Gilner, F. H., \& Munz, D. C. (1998). The measurement of imagery vividness: A test of the reliability and validity of the Vividness of Visual Imagery Questionnaire and the Vividness of Movement Imagery Questionnaire. Journal of Mental Imagery, 22, 125-136.

Goldzweig, G., Gamliel, E., \& Peer, E. (2009). The Sport Imagery Ability Measure (SIAM): Comparison of the Visual Analogue Scale with a Likert Scale in Hebrew Translation. Proceedings: The $12^{\text {th }}$ World Congress of Sport Psychology. Marrakesh, Morocco: ISSP.

Gregg, M., \& Hall, C. (2006). Measurement of motivational imagery abilities in sport. Journal of Sports Sciences, 24, 961-971.

Hair, J. F., Black, W. C., Babin, B. J., \& Anderson, R. E. (2010). Multivariate Data Analysis ( $7^{\text {th }}$ ed.). Upple Saddle River, NJ: Prentice-Hall.

Hall, C. R. (2001). Imagery in sport and exercise. In: R. N. Singer, H. A. Hausenblas, \& C. M. Janelle (eds.), Handbook of research on sport psychology ( $2^{\text {nd }}$ ed., pp. 529-549). New York: John Wiley \& Sons Inc.

Hall, C., Mack, D., Paivio, A., \& Hausenblas, H. (1998). Imagery use by athletes: Development of the Sport Imagery Questionnaire. International Journal of Sport Psychology, 29, 73-89.

Hall, C. R., \& Martin, K. A. (1997). Measuring movement imagery abilities: A revision of the movement imagery questionnaire. Journal of Mental Imagery, 21, 143-154.
Hall, C. R., Pongrac, C., \& Buckolz, E. (1985). The measurement of imagery ability. Human Movement Science, 4, 107-118.

Hardy, L., \& Callow, N. (1999). Efficacy of external and internal visual imagery perspectives for the enhancement of performance on task in which form is important. Journal of Sport and Exercise Psychology, 21, 95-112.

Hooper, D., Coughlan, J., \& Mullen, M. R. (2008). Structural Equation Modeling: Guidelines for Determining Model Fit. Electronic Journal of Business Research Methods, 6, 53-60.

Hu, L., \& Bentler, P. M. (1999). Cutoff criteria for fit indices in covariance structure analysis: Conventional criteria versus new alternatives. Structural Equation Modeling, 6, 1-55.

Isaac, A. R., Marks, D. F., \& Russell, D. G. (1986). An instrument for assessing imagery of movement: The vividness of Movement Imagery Questionnaire (VMIQ). Journal of Mental Imagery, 10, 23-30.

Isaac, A. R., \& Marks, D. F. (1994). Individual differences in mental imagery experience: developmental changes and specialization. British Journal of Psychology, 85, 479-500.

Kline, P. (2000). The handbook of psychological testing ( $2^{\text {nd }}$ ed.). London: Routledge. Cite in: Cruise, S. M., Lewis, C. A., \& McGuckin, C. (2006). Test-retest reliability of self-estimated intelligence: Temporal stability over four time periods. Social Behavior and Personality, 34, 1179-1188.

Lequerica, A., Rapport, L., Axelrod, B. N., Telmet, K., \&Whitman, R. D. (2002). Subjective and objective assessment methods of mental imagery control: Construct validation of self-report measures. Journal of Clinical and Experimental Neuropsychology, 24, 1103-1116.

Martens, R. (1982). Imagery in sport. Paper presented at he conference on Medical and Scientific Aspects of Elitism in Sport, Brisbane, Australia.

Morris, T., Spittle, M., \& Perry, C. (2004). Mental imagery in sport. In: T. Morris, \& J. Summers (eds.), Sport Psychology: Theory, applications, and issues ( $2^{\text {nd }}$ ed., pp. 344-383). Brisbane, Australia: Wiley.

Morris, T., Spittle, M., \& Watt, A. (2005). Imagery in Sport. Champaign, IL: Human Kinetics.

Oishi, K., \& Maeshima, T. (2004). Autonomic nervous system activities during motor imagery in elite athletes. Journal of Clinical Neurophysiology, 21, 170-179.

Orlick, T. (2004). Feeling Great. Teaching children to excel at living ( $3^{\text {rd }}$ ed.). Ottawa: Creative Bound Inc.

Orlick, T. (2008). In pursuit of excellence. How to win in sport and life through mental training ( $4^{\text {th }}$ ed.). Champaign, IL: Human Kinetics.

Richardson, J. T. E. (1999). Imagery. Hove: Psychology Press.

Richardson, A. (1994). Individual differences in imaging: Their measurement, origins, and consequences. Amityville, NY: Baywood. 
Roberts, R., Callow, N., Hardy, L., Markland, D., \& Bringer, J. (2008). Movement imagery ability: Development and assessment of a revised version of the vividness of movement imagery questionnaire. Journal of Sport \& Exercise Psychology, 30, 200-221.

Rodgers, W., Hall, C. R., \& Buckolz, E. (1991). The effect of an imagery training program on imagery ability, imagery use, and figure skating performance. Journal of Applied Sport Psychology, 3, 109-125.

Ruiz, M. C., \& Watt, A. P. (2014). Psychometric characteristics of the Spanish version of the Sport Imagery Questionnaire. Psicothema, 26, 267-272.

Sheehan, P. W., Ashton, R., \& White, K. (1983). Assessment of mental imagery. In: A. A. Sheikh (ed.), Imagery: Current theory, research, and application (pp. 189-221). New York: Wiley.

Vasta, R., Haith, M. M., \& Miller, S. (1995). Psychology of child. Warsaw: PWN.

Vealey, R., \& Greenleaf, C. A. (1998). Seeing is believing: Understanding and Using imagery in sport. In: J. M. Williams (ed.), Applied sport psychology: Personal growth to peak performance ( $3^{\text {rd }}$ ed., pp. 247-283). Mountain View, CA: Mayfield.

Vealey, R. S., \& Walter, S. M. (1993). Imagery training for performance enhancement and personal development. In: J. M. Williams (ed.), Applied sport psychology: Personal growth to peak performance $\left(2^{\text {nd }}\right.$ ed., 200-224). Mountain View, CA: Mayfield.

Vealey, R. S. (1986). Imagery training for performance enhancement. In: J. M. Wiliams (ed.), Applied sport psychology: Personal growth to peak performance ( $1^{\text {st }}$ ed., pp. 209-231). Mountain View, CA: Mayfield.

Vongjaturapat, N., Morris, T., Bhasavanija, T., Singhnoy, C., Julvanichpong, T., Tanpanich, A., Pattanamontri, C., Montree, A., Sinpatt, A., Prachakul, W., \&Watt, A. P. (2010). Confirmatory Factor Analysis of the Thai language version of the Sport Imagery Ability Measure, Imagery in Sport Symposium, Proceedings: 27th International Congress of Applied Psychology (ICAP 2010). Melbourne, Australia.

Watt, A. P., Jaakkola, T. T., \& Morris, T. (2006). Reliability and factor structure of the Finnish version of the Sport Imagery Questionnaire. Perceptual and Motor Skills, 103, 107-114. DOI: org/10.2466/pms.

Watt, A., \& Morris, T. (1999). Information Manual for the Sport Imagery Ability Measure (SIAM). Victoria University of Technology.

Watt, A. (2003). Development and validation of the Sport Imagery Ability Measure (PhD dissertation). Victoria University, Melbourne, Australia.

Watt, A. P., \& Morris, T. (2001). Criterion validity of the Sport Imagery Ability Measure (SIAM). In: A. Papaioannou, M. Goudas, \& Y. Teodorakis (eds.), Proceedings of the $10^{\text {th }}$ World Congress of Sport Psychology (vol. 2, pp. 60-62). Skiathos, Greece.
Watt, A. P., Morris, T., \& Andersen, M. B. (2004). Issues in the development of a measure of imagery ability in sport. Journal of Mental Imagery, 28, 149-180.

Weibull, F., Johnson U., \& Watt, A. (2009). Psychometric analysis of the Swedish version of the Sport Imagery Ability Measure, Proceedings: The $12^{\text {th }}$ World Congress of Sport Psychology. Marrakesh, Morocco, ISSP.

Williams, S. E., \& Cumming, J. (2011). Measuring athlete imagery ability: the sport imagery ability questionnaire. Journal of Sport \& Exercise Psychology, 33, 416-440.

Williams, S. E., Cumming, J., Ntoumanis, N., Nordin-Bates, S. M., Ramsey, R., \& Hall, C. (2012). Further validation and development of the Movement Imagery Questionnaire. Journal of Sport \& Exercise Psychology, 34, 621-646. 